https://dx.doi.org/10.4314/ijs.v23i2.2

Ife Journal of Science vol. 23, no. 2 (2021)

\title{
THE DISTRIBUTION OF EXTENDED-SPECTRUM BETA-LACTAMASE GENES IN FOMITES, HEALTHCARE WORKERS, AND PATIENTS FROM TWO HOSPITALS IN LAGOS STATE, NIGERIA
}

\author{
Egwuatu, T. O.*, Ishola, O. D. and Oladele, O. E. \\ Department of Microbiology, University of Lagos, Akoka, Lagos, Nigeria. \\ *Corresponding author: tegwuatu@unilag.edu.ng \\ (Received: $28^{\text {th }}$ March, 2021; Accepted: $13^{\text {th }}$ May, 2021)
}

\begin{abstract}
Antibiotics resistance is a rapidly emerging issue through the misuse of antibiotics to treat human and animalrelated infections. The use of beta-lactams has increased considerably since its discovery so also resistant genes leading to Extended-Spectrum Beta-Lactamases (ESBL) mediated by the presence of bla $_{\text {CTX-M }}$, bla $_{\text {TEM, }}$, and bla $\mathrm{SHV}_{\mathrm{SHV}}$ genes present in most Gram-negative bacteria. This study aimed to detect the widespread distribution of ESBL genes from fomites, healthcare workers, and patients suffering from urinary tract infection in two hospitals in Lagos state, Nigeria. A total of 150 swab samples were collected from fomites, health care workers, and catheters of patients suffering from urinary tract infection (UTI). Antibiotics susceptibility test was performed by KirbyBauer technique according to CLSI guidelines. Organisms that tested positive phenotypically for ESBL were subjected to PCR for molecular analysis. ESBL prevalence rate of $21.8 \%$ and a carbapenemase-resistance rate of $16.7 \%$ were recorded. The ESBL producing isolates showed the highest resistance to ceftriaxone $(82.4 \%)$ and the least resistance to tigecycline (5.9\%). The existence of $\mathrm{bla}_{\text {СТХ-м }}$ and $\mathrm{bla}_{\mathrm{TEM}}$ was detected in $76.5 \%$ and $17.6 \%$ of the isolates respectively, while bla $\mathrm{SHV}_{\mathrm{S}}$ encoding gene was not detected in this study. The distribution of bla genes detected in this study is of great concern which necessitates strict control measures in the usage of antibiotics especially the third-generation cephalosporin. In summary, the presence and distribution of ESBL encoding genes within two hospitals in Lagos were tested and the highest occurrence was recorded in bla СTX-м $_{\text {gene }}$ reducing and limiting the available treatment option for infections.
\end{abstract}

\section{INTRODUCTION}

The number of resistant microbial strains, geographic areas affected by drug resistance, and the extent of resistance in clinical isolates continues to escalate therefore contributing to one of the most serious jeopardies to global public health in the $21^{\text {st }}$ century (Lewis and Allen, 2001; Fair and Tor, 2014; Amann et al., 2019). The spread of Extended-Spectrum Beta-Lactamase (ESBL) and carbapenemase-producing Enterobacteriaceae has been reported globally in increasing numbers (Haller et al., 2018). Extended-Spectrum BetaLactamases (ESBLs) are transmissible $\beta$ lactamases capable of hydrolysing thirdgeneration cephalosporin and aztreonam but are inhibited by clavulanic acid, tazobactam, or sulbactam (Rawat and Nair, 2010; Shaikh et al., 2015). $\beta$-lactamases may be chromosomally encoded or plasmid-mediated encoding genes that can be exchanged between bacteria in a process of vertical gene transfer (from parents to offspring) or horizontal gene transfer (from a donor to a recipient that is not its offspring (Rawat and Nair, 2010; Shaikh et al., 2015). These beta-lactamases have been found worldwide in many different species of the Enterobacteriaceae family and other Gram-negative bacteria such as Pseudomonas spp. and Acinetobacter spp (Lewis and Allen, 2001). The major agents of the propagation of these strains are misuse and over usage of antibiotics in humans, animals, the circulation of antibiotic residues, and ESBL in the environment (Huijbers et al., 2014; Hou et al., 2015; Gundran et al., 2019).

Curiously, ESBLs are most commonly detected in Klebsiella pneumoniae (Podschun and Ullmann, 1998). This organism is a cause of significant community-and hospital-acquired infections (Paterson et al., 2003). Multidrug-resistant clinical isolates have important clinical consequences in community and hospital settings ( $\mathrm{Li}$ and Webster, 2018). This organism is a cause of significant community-and hospital-acquired infections (Paterson et al., 2003). Multidrug-resistant clinical isolates have important clinical consequences in community and hospital settings ( $\mathrm{Li}$ and Webster, 2018). They have evolved as a global concern, exacerbated by under-reporting in some regions 
of Africa and the world at large (Essack et al., 2017). The tendency of these isolates to concurrently be resistant to other groups of antibiotics significantly limits the selection of antibiotics for the treatment of infections. The development of resistance to third-generation cephalosporin is attributed to the production of beta-lactamases including Extended-Spectrum Beta-Lactamases (ESBLs) and carbapenemase.

The most significant beta-lactamase genes are variants of CTX-M, SHV, and TEM which have broadened the substrate specificity against ceftazidime, cefotaxime, and ceftriaxone (Oteo et al., 2006). This study was carried out to investigate the presence of ESBL resistant genes in clinical isolates and to check the frequency of thirdgeneration cephalosporin resistance and distribution of key genetic determinants in Lagos state, Nigeria.

\section{MATERIALS AND METHODS}

\section{Study Design}

This is a cross-sectional study involving two public hospitals in Lagos State namely Lagos University Teaching Hospital (LUTH) and Randle general hospital, Surulere, Lagos. The isolates were collected from intensive care unit centres in both hospitals.

\section{Samples Collection}

Fomite samples were collected from intensive care unit door handles, patients' beds, waste bin, and thermometers at random using sterile swab sticks which were placed in plain bottles containing the transport medium (peptone water). Hand swabs were collected from health care workers' using sterile swab sticks moistened with sterile normal saline for the organisms to adhere more. The patient's swab samples were collected from the catheter tips of patients suffering from urinary tract infection.

\section{Bacterial Identification and Characterization}

The specimens were inoculated on MacConkey agar (Oxoid) and incubated for 24 hours aerobically at $37^{\circ} \mathrm{C}$. Distinct colonies' appearance and characteristics of the isolates on MacConkey agar were noted and the pure isolates were then subjected to Gram staining using standard procedures to identify 78 non-duplicate Gramnegative rods. All suspected isolates of Enterobacteriaceae were confirmed by Microbact Gram-negative identification systems (Oxoid, United Kingdom) according to the manufacturer's instructions.

\section{Antibiotics Susceptibility Testing}

Antibiotics sensitivity was determined using the Kirby-Bauer disk diffusion method (Bauer et al., 1978) on Mueller-Hinton Agar using commercially available single antibiotics paper disks (Oxoid, UK). The antibiotics used were amoxicillin-clavulanate $(30 \mu \mathrm{g})$, ceftazidime (30 $\mu \mathrm{g})$, cefotaxime $(30 \mu \mathrm{g})$, ceftriaxone $(30 \mu \mathrm{g})$, ciprofloxacin $(5 \mu \mathrm{g})$, gentamicin $(10 \mu \mathrm{g})$, chloramphenicol $(30 \mu \mathrm{g})$, aztreonam $(30 \mu \mathrm{g})$, colistin $(10 \mu \mathrm{g})$, tetracycline $(30 \mu \mathrm{g})$, tigecycline $(15$ $\mu \mathrm{g})$, meropenem $(10 \mu \mathrm{g})$, and imipenem $(10 \mu \mathrm{g})$.

A discrete colony of the isolate was picked using a sterile swab stick and was suspended into sterile saline water to the density of 0.5 MacFarland turbidity standard according to the Clinical Laboratory Standards Institute (CLSI) 2017 guideline. Excess saline water was drained from the swab stick to prevent over inoculation of the organism on Mueller-Hinton agar. Drained swab sticks were used to inoculate the standardized organisms to MacFarland standard to dry Mueller Hinton agar plates in such a way that ensures uniform growth of the organism across the plates. The antibiotic discs were placed on the plates within 15 minutes to prevent the organism from growing before the placement of discs. The plates were incubated aerobically for 18 hours at $37^{\circ} \mathrm{C}$. The zone of inhibition surrounding each disk was measured with a ruler and interpreted as either resistant or sensitive according to CLSI 2017 standard.

\section{Extended-Spectrum Beta-Lactamase Test}

The double synergy test (DDST) method described by CLSI (2017) was employed. A standardized inoculum of the bacteria was inoculated using sterile swab sticks on MuellerHinton Agar with turbidity adjusted to 0.5 MacFarland standard (Oxoid, UK). Amoxicillin/Clavulanic acid $(30 \mu \mathrm{g})$ disc was placed at the centre of the inoculated MuellerHinton Agar. Ceftazidime $(30 \mu \mathrm{g})$ and cefotaxime 
$(30 \mu \mathrm{g})($ Oxoid UK) were placed $25 \mathrm{~mm}$ centre-tocentre away from the amoxicillin/clavulanic acid disc. The plates were incubated aerobically at 37 ${ }^{\circ} \mathrm{C}$ for 18 hours. After incubation, ESBL production was detected by the measurement of the zone of inhibition of either or both ceftazidime and cefotaxime discs towards amoxicillin/clavulanic acid discs.

\section{DNA Extraction (By Boiling)}

The phenotypically positive isolates were cultured on Nutrient Agar and incubated at $37^{\circ} \mathrm{C}$ for 24 hours. This was done to provide freshly cultured bacteria for accurate results and was then put in a $1.5 \mathrm{ml}$ micro-centrifuge tube containing $1000 \mu \mathrm{l}$ of sterile water. The isolates in the microcentrifuge tubes were homogenized using a vortex mixer and centrifuged at 10,000 revolutions per minute for 5 mins. The supernatants were removed and the pellet was re-suspended in $200 \mu \mathrm{l}$ of sterile water, vortexed, and re-centrifuged for another 5 mins. The supernatant in each tube was discarded and the pellet was collected and boiled at $100^{\circ} \mathrm{C}$ for 10 mins. The micro-centrifuge tubes were cooled in ice for 10 mins and centrifuged at
$10,000 \mathrm{rpm}$ for about 5 mins. Then, the supernatants were transferred to fresh $1.5 \mathrm{ml}$ micro-centrifuge tubes and stored at $-20{ }^{\circ} \mathrm{C}$ in a deep freezer for PCR analysis.

\section{Multiplex PCR (Polymerase Chain Reaction) Amplification}

A multiplex PCR reaction was carried out to identify bla $\mathrm{CTX}_{\mathrm{CT}}, \mathrm{bla}_{\mathrm{SH},}$ and $\mathrm{bla}_{\mathrm{TEM}}$ (as shown in table 1). PCR was performed in DNA thermal cycler using Maxima Hot Start PCR Master Mix kit (2x), (Cat. No K1051) according to the manufacturer's instruction. It is a ready-to-use mix containing Maxima hot start Taq DNA polymerase, optimized hot-start PCR buffer, $\mathrm{MgCI}_{2}$, and ddNTPs. The reaction was performed in a $20 \mu \mathrm{l}$ volume containing $2 \mu \mathrm{M}$ Maxima hot start PCR master mix (2x), the primers $(0.2 \mu \mathrm{M}$ each), and 2 $\mu \mathrm{l}$ of extracted DNA. Nuclease-free water was used to make up $20 \mu \mathrm{l}$ volumes. The amplification profile was done according to Jemima and Verghese's (2008) and negative control was amplified with each run (Jemima and Verghese, 2008).

Table 1: Primers Used in this Study

\begin{tabular}{|c|c|c|c|c|}
\hline $\begin{array}{l}\text { GENE } \\
\text { TARGET }\end{array}$ & PRIMER & $\begin{array}{l}\text { SEQUENCE (5' TO 3' AS } \\
\text { SYNTHESIZED) }\end{array}$ & $\begin{array}{l}\text { PRODUC } \\
\mathrm{T} \\
\text { SIZE (bp) }\end{array}$ & $\begin{array}{l}\text { ANNEALIN } \\
\text { G } \\
\text { TEMP }\left({ }^{\circ} \mathrm{C}\right)\end{array}$ \\
\hline SHV & $\begin{array}{l}\text { SHV-F } \\
\text { SHV-R }\end{array}$ & $\begin{array}{l}\text { ATGCGTTATATTCGCCTGT } \\
\text { TGCTTTGTTATTCGGGCCAA }\end{array}$ & 753 & 55 \\
\hline СТX-M & $\begin{array}{l}\text { CTX-M-F } \\
\text { CTX-M-R }\end{array}$ & $\begin{array}{l}\text { TTGCGATGTGCAGTACCAGTA } \\
\text { CGATATCGTTGGTGGTGCCAT }\end{array}$ & 543 & 62 \\
\hline TEM & $\begin{array}{l}\text { TEM-F } \\
\text { TEM-R }\end{array}$ & $\begin{array}{l}\text { AAACGCTGGTGAAAGTA } \\
\text { AGCGATCTGTCTATCCT }\end{array}$ & 822 & 43 \\
\hline
\end{tabular}

\section{Agarose Gel Electrophoresis of Amplification Product}

The amplification product was separated on a $1.5 \%$ agarose gel and electrophoresis was carried out at $80 \mathrm{~V}$ for 80 minutes. After electrophoresis, DNA bands were visualized by ethidium bromide staining and a $100 \mathrm{bp}$ DNA ladder was used as the DNA molecular weight standard.

\section{RESULTS}

A total of 150 swab samples were processed and the isolates were identified using the Gram staining procedure. The identified
Enterobacteriaceae were confirmed using GNB 24E Microbact kit (Oxoid, UK) and 78 isolates were obtained. Of the 78 isolates, eight different organisms were identified. Klebsiella ozaenae had the highest number of occurrence- $23(29.4 \%)$ and other isolates obtained in their order of prevalence are: Klebsiella pneumoniae 14 (17.9\%), Escherichia coli 10 (12.8\%), Raoultella ornithinolytica 9 (11.5\%), Pantoea agglomerans 8 (10.3\%), Pseudomonas mallei 6 (7.7\%), Proteus mirabilis 7 (7.7\%) and Escherichia fergusonni $2(2.6 \%)$ being the least. Table 2 shows the distribution of the different ESBLproducing isolates and their encoding genes 
across the two hospital centres in this study.

Of the 78 isolates identified, 17 ESBL positive isolates were confirmed using double disc synergy test and were subjected to molecular analysis for the confirmation of resistant genes. The results showed the highest percentage of $13(76.5 \%)$ for CTX-M gene followed by $3(17.6 \%)$ for TEM gene; $3(17.6 \%)$ isolates showed no bla gene when analysed using PCR. However, the coexistence of bla $_{\text {СТX-M }}$ and bla $_{\text {TEM }}$ gene was detected in $2(11.8 \%)$ of the 17 ESBL-producing isolates. Figure 1 shows a picture of a typical phenotypic ESBL producing isolate. Table 2 and figure 2 show the distribution of genes of the ESBL positive isolates.

A total of 13 antibiotics were used to test for
ESBL and non-ESBL producing isolates (Table 3, Figure 3). Antibiotics susceptibility profile of the ESBL producing isolates includes tigecycline 16 $(94.1 \%)$, colistin $14(82.3 \%)$, meropenem 14 $(82.3 \%)$, imipenem $14(82.3 \%)$, gentamicin 13 (76.5\%), ceftazidime $13(76.5 \%)$, amoxicillinclavulanic acid $10(58.8 \%)$, tetracycline 10 $(58.8 \%)$, cefotaxime $8(47.1 \%)$, chloramphenicol 7 $(41.2 \%)$, aztreonam $6(35.3 \%)$, ciprofloxacin 5 $(29.4 \%)$ and ceftriaxone $3(17.6 \%)$. The antibiotics resistance profile of the ESBL producing isolates showed the highest resistance of $14(82.4 \%)$ to ceftriaxone and the least resistance to tigecycline 1 (5.9\%). The antibiotics profile of both ESBL and non-ESBL producing isolates (Figure 2) shows that imipenem is the most susceptible antibiotics $(92.3 \%)$ and ceftriaxone is the least susceptible antibiotics $(26.9 \%)$.

Table 2: Distribution of the Different ESBL Producing Isolates and their Encoding Genes across the Two Hospital Centres in this Study

\begin{tabular}{llllll}
\hline S/N & Isolate name & $\begin{array}{l}\text { Sample } \\
\text { Location }\end{array}$ & Source of Isolates & $\begin{array}{l}\text { Phenotypic } \\
\text { presence } \\
\text { of ESBL }\end{array}$ & Bla-gene \\
\hline 1 & Klebsiella ozaenae & Randle & Patient & Yes & CTX-M and TEM \\
2 & Klesiella pneumoniae & Randle & Fomite & Yes & CTX-M \\
3 & Klebsiella pneumoniae & LUTH & Patient & Yes & CTX-M \\
4 & Raoultella ornithinolytica & LUTH & Patient & Yes & CTX-M \\
5 & Raoultella ornithinolytica & LUTH & Patient & Yes & CTX-M \\
6 & Raoultella ornithinolytica & Randle & Health care worker & Yes & TEM \\
7 & Klebsiella ozaenae & LUTH & Fomite & Yes & NONE \\
8 & Klebsiella pneumoniae & LUTH & Patient & Yes & CTX-M \\
9 & Klebsiella ozaenae & Randle & Fomite & Yes & CTX-M and TEM \\
10 & Klebsiella ozaenae & Randle & Patient & Yes & CTX-M \\
11 & Klebsiella ozaenae & LUTH & Fomite & Yes & CTX-M \\
12 & Pseudomonas mallei & Randle & Fomite & Yes & CTX-M \\
13 & Klebsiella ozaenae & LUTH & Patient & Yes & CTX-M \\
14 & Pantoea agglomerans & LUTH & Fomite & Yes & CTX-M \\
15 & Proteus mirabilis & Randle & Health care worker & Yes & CTX-M \\
16 & Klebsiella ozaenae & Randle & Health care worker & Yes & NONE \\
17 & Klebsiella pneumoniae & Randle & Health care worker & Yes & NONE \\
\hline
\end{tabular}


Table 3: Antibiotics Susceptibility Profile of all the Isolates

\begin{tabular}{lllll}
\hline S/N & Antibiotics & $\begin{array}{l}\text { Antibiotics } \\
\text { susceptibility }\end{array}$ & $\begin{array}{l}\text { Total number of } \\
\text { isolates antibiotics } \\
\text { was tested on }\end{array}$ & $\begin{array}{l}\text { Percentage (\%) } \\
\text { susceptibility }\end{array}$ \\
\hline 1 & Meropenem & 71 & 78 & 91.0 \\
2 & Imipenem & 72 & 78 & 92.3 \\
3 & Chloramphenicol & 41 & 78 & 52.6 \\
4 & Ciprofloxacin & 25 & 78 & 32.1 \\
5 & Tetracycline & 41 & 78 & 52.6 \\
6 & Gentamicin & 44 & 78 & 56.4 \\
7 & Ceftriaxone & 21 & 78 & 26.9 \\
8 & Amoxicillin-Clavulanic acid & 32 & 78 & 41.0 \\
9 & Tigecycline & 70 & 78 & 89.7 \\
10 & Aztreonam & 32 & 78 & 41.0 \\
11 & Ceftazidime & 43 & 78 & 55.1 \\
12 & Cefotaxime & 34 & 78 & 43.6 \\
13 & Colistin & 55 & 78 & 70.5 \\
\hline
\end{tabular}

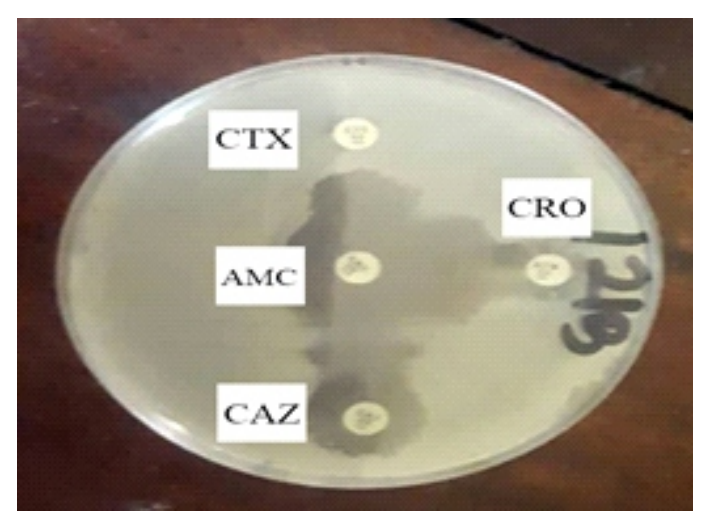

Figure 1: ESBL-producing Organism (Klebsiella ozaenae)

The cork (key shape) in-between ceftazidime, amoxicillin-clavulanic acid, and ceftriaxone indicates the synergy that occurs as a result of ESBL enzyme production.

Abbreviation: CAZ-Ceftazidime, AMC- Amoxicillin-Clavulanic acid, CTX-Cefotaxime, CRO-Ceftriaxone.

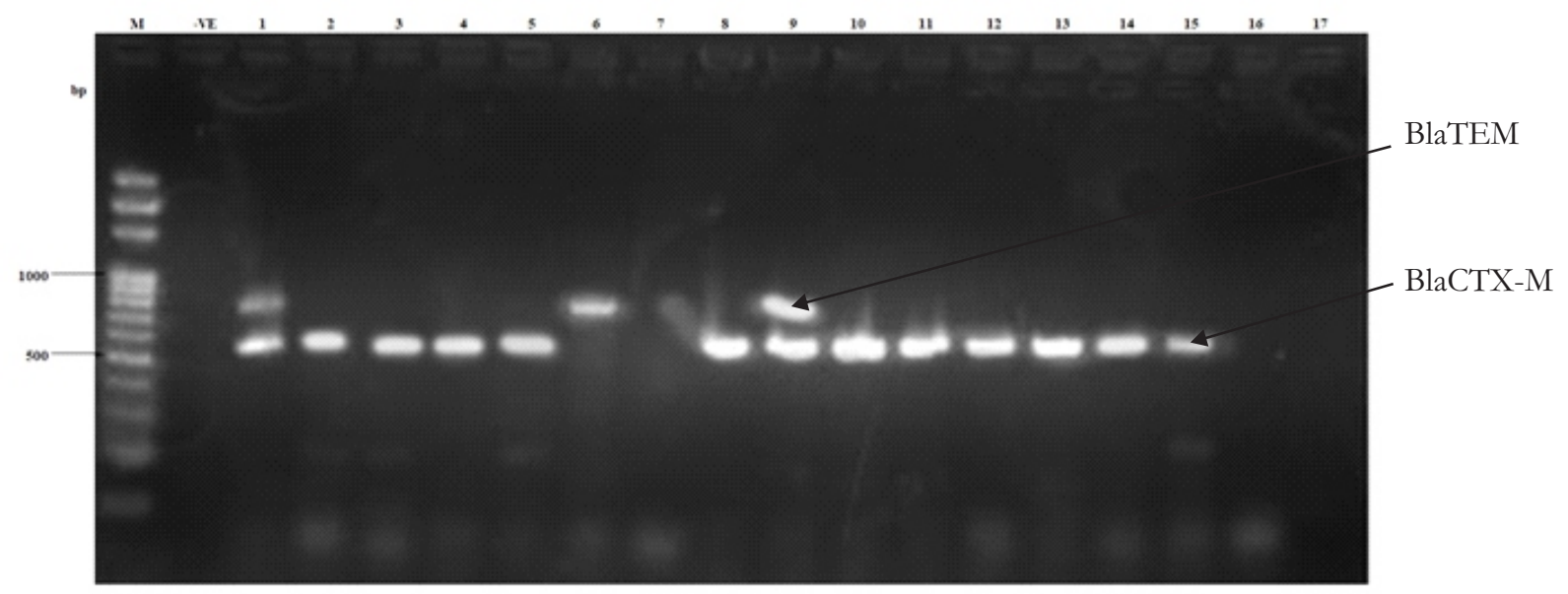

Figure 2: Gene Distribution among ESBL-producing Isolates

Lane M: DNA Marker (100bp), Lane -VE: Negative Control, Lanes 1-17- Test organisms, Lane 1, 2, 3, 4, 5, 8, 9, 10, 11, 12, 13,14, and 15- CTX-M gene, Lane 1, 6 and 9- TEM gene, Lanes 1 and 9 shows both CTX-M and TEM gene, Lanes 7, 16 and 17- No gene was seen (the representative isolates for these genes are in table 2). 


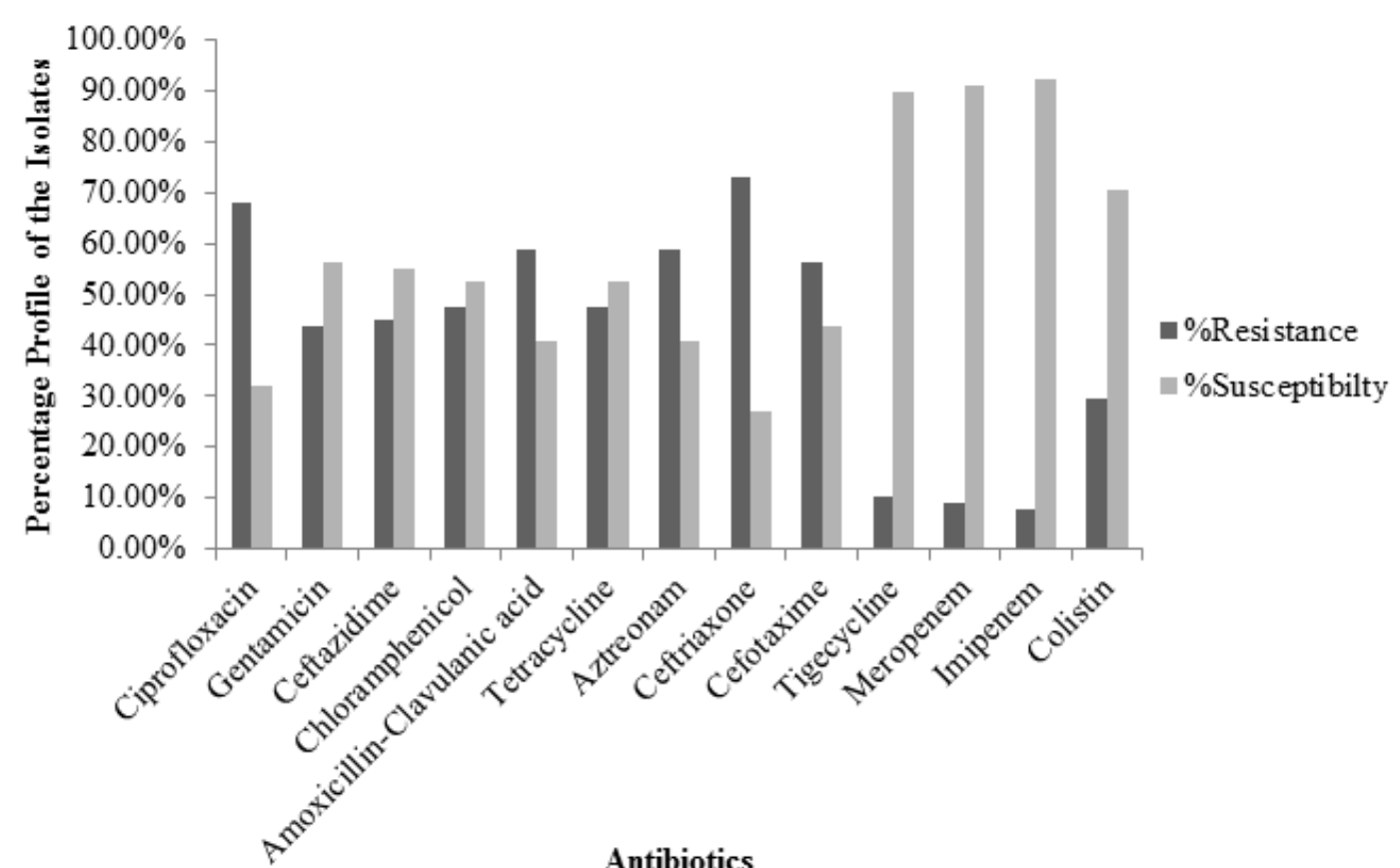

Antibiotics

Figure 3: Antibiotics Profile of the ESBL and non-ESBL Producing Isolates

\section{DISCUSSION}

The overall prevalence of ESBL producers in this study was confirmed phenotypically to be $21.7 \%$ ( $n=17 / 78$ isolates). This result is similar to a recent report around the same study area by Jewoola et al., (2020) that had a total carriage rate of clinical isolates of $25.3 \%$ ESBL positive isolates and is in contrast to the findings of Bajpai et al., (2014) and Ramesh and Sumathi (2008) that reported ESBL resistance in India at 36.8\% and $71.5 \%$ respectively. This observed variance may be attributed to differences in study design, geographical areas where the study was conducted, the procedure for specimen selection, or screening techniques used in the laboratory centres (Ashrafian et al., 2013; Schechner et al., 2013).

The isolates were screened for ESBL resistance using antibiotics discs. Of the 17 phenotypically positive ESBL isolates, $12(70.5 \%)$ were detected by ceftazidime, $3(17.6 \%)$ by cefotaxime, and 2 $(11.7 \%)$ by ceftriaxone as ESBL producers. This shows that ceftazidime is the best ESBL screening agent among the three cephalosporins used in this study. This conforms to the finding of Akujobi and Ewuru (2010) who reported that ceftazidime detected $80 \%$ of the ESBL-producing isolates in their study.
This report is in agreement with the findings of Pitout et al., (2007) that demonstrated the molecular epidemiology of CTX-M gene in the Calgary Health Region and proved that CTX-M genes are now widely distributed beta-lactamase genes among the ESBL genes in both nosocomial infection and community-acquired pathogens. The study is however in contrast to the findings of Cruz and Hedreyda, (2017) where it was reported that TEM-type is more prevalent in clinical isolates from Filipinos.

The detection of ESBL isolates in fomites and health care workers in this study suggests the possible spread of the pathogen in the hospital environment which could be a means for transmission of hospital-acquired infection (Huijbers et al., 2014; Day et al., 2019). In this study, a significantly low prevalence of ESBL producers was isolated from health care workers compared to patients. Good hand-washing and hygienic practices were observed among the health care workers in this study which should be emulated in every healthcare setting (Ellingson et al., 2014; Sendall et al., 2019). The high prevalence of bla м gene in this study is of clinical importance because of its implication against third-generation 
cephalosporins (cefotaxime and ceftriaxone). Resistance to ceftazidime was also recorded supporting the report of Rossolini et al., (2008).

Co-existence of multiple bla $\mathrm{CTX}_{\mathrm{CT}}$ and $\mathrm{bla}_{\mathrm{TEM}}$ gene was observed in $2(11.7 \%)$ ESBL producing isolates but no bla $_{\mathrm{SHV}}$ was detected similar to the study of Gundran et al., (2019). The coexistence of different beta-lactamase genes within the same isolates has been reported by several investigators (Bai et al., 2017; Gundran et al., 2019) The presence of multiple ESBL resistance genes could result in retained resistance to beta-lactamases despite the reduced expression of one or two genes, therefore, making it more difficult to treat since the isolates will most likely be resistant to more antibiotics and most third-generation cephalosporins (Gundran etal., 2019).

The current study supports previous reports of the spread of ceftriaxone resistance among Enterobacteriaceae worldwide (Goldstein et al., 1995; Al Kraiem et al., 2018; Gashe et al., 2018). This could be due to the transfer of resistant genes by resistant organisms to their offspring by replication (vertical gene transfer) or by conjugation where the plasmids carrying the resistant gene are exchanged between the nearby organisms through a process called horizontal gene transfer (Baral et al., 2012).

Colistin a last-resort antibiotic showed a resistance of $43.6 \%$ which is an increase compared to the report of Obasi et al., (2018) but not up to that of Otokunefor et al., (2019) that recorded 60\% colistin resistance in Port Harcourt, Nigeria. This shows a worrisome spread of colistin resistance in Nigeria. The spread of these resistance genes needs to be deeply investigated and measures to overcome the widely disseminating antibiotic resistance should be researched and satisfactorily executed. Carbapenem regarded as the last resort antibiotics of choice for the treatment against infections caused by ESBL-producing isolates (Shaikh et al., 2015; Rodriguez-Baño et al., 2018) showed $7.7 \%$ resistance to imipenem and $9.0 \%$ resistance to meropenem. Although the rate of carbapenemase resistance in this study compared to some other studies in Nigerian hospitals might be low (Olalekan et al., 2020; Oli et al., 2019), it should however be noted that this study established the presence of carbapenemaseresistant Enterobacteriaceae in clinical settings. It should also be noted that the incidence of carbapenemase-producing isolates varies from one region to another as well as from time to time across seasons (Alaka et al., 2019).

Nonetheless, the study supports the report of Alaka et al., (2019) that both Gram-negative and Gram-positive organisms are predominantly sensitive to carbapenems but less susceptible to third-generation cephalosporins. It is evident that strict control measures and judicious use of antibiotics in healthcare centres are needed to avoid an uncontrollable increase in resistance to these antibiotics in this region.

\section{CONCLUSION}

This study established the presence and distribution of ESBL encoding genes within the community. Based on the results of this study, we advise that health care workers should inculcate good hygiene and management practices especially within the hospital environment and should be included in the study of detection of Extended-Spectrum Beta-Lactamases as this study shows that health care practitioners can act as a carrier of these enzymes from the hospital to the community. There is a need to put in place strict control measures in the usage of polymyxin, third-generation cephalosporins, and carbapenem antibiotics as resistance to these classes of antibiotics have been reported in high numbers in other studies and were confirmed in this study. This further reduces and limits the available treatment option for infections and could lead to the emergence of untreatable infections if preventive measures are not put in place.

\section{ACKNOWLEDGMENTS}

The authors wish to acknowledge the staff of hospitals where the isolates were collected.

\section{REFERENCES}

Akujobi, C. and Ewuru, C. (2010). Detection of extended spectrum beta-lactamases in gram negative bacilli from clinical specimens in a teaching hospital in South eastern Nigeria. Nigerian Medical Journal, 51(4): 141-146.

Al Kraiem, A. A., Yang, G., Al Kraiem, F. and 
Chen, T. (2018). Challenges associated with ceftriaxone resistance in Salmonella. Frontiers in Life Science, 11(1): 26-34.

Alaka, O. O., Orimolade, E. A., Ojo, O. O. and Onipede, A. O. (2019). The phenotypic detection of carbapenem resistant organisms in orthopaedic wound infections in Ile-Ife, Nigeria. Acta Scientific Microbiology, 2(2): 35-42.

Amann, S., Neef, K. and Kohl, S. (2019). Antimicrobial resistance (AMR). European Journal of Hospital Pharmacy, 26(3): 175177.

Ashrafian, F., Askari, E., Kalamatizade, E., Javad, M., Shahroodi, G., Naderi-Nasab, M. and Naderi-Nasab, M. (2013). The frequency of extended spectrum beta lactamase (ESBL) in Escherichia coli and Klebsiella pneumoniae: a report from Mashhad, Iran. Journal of Medical Bacteriology, 2(2): 12-1912.

Bai, L., Wang, L., Yang, X., Wang, J., Gan, X., Wang, W., Xu, J., Chen, Q., Lan, R., Fanning, S. and Li, F. (2017). Prevalence and molecular characteristics of extended-spectrum $B$-lactamase genes in Escherichia coli isolated from diarrheic patients in China. Frontiers in Microbiology, 8(FEB): 1-8.

Bajpai, T., Pandey, M., Varma, M. and Bhatambare, G. (2014). Prevalence of extended spectrum beta-lactamase producing uropathogens and their antibiotic resistance profile in patients visiting a tertiary care hospital in central India: Implications on empiric therapy. Indian Journal of Pathology and Microbiology, 57(3): 407.

Baral, P., Neupane, S., Marasini, B., Ghimire, K., Lekhak, B. and Shrestha, B. (2012). High prevalence of multidrug resistance in bacterial uropathogens from Kathmandu, Nepal. BMC Research Notes, 5(1): 38.

Bauer, A. W., Kirby, W. M. M., Sherris, J. C., Turck, A. M. (1966). Antibiotic susceptibility testing by a standardized single disk method. American Journal of Clinical Pathology, 45(3): 493-496.

Cruz, M. C. and Hedreyda, C. T. (2017). Detection of plasmid-borne $\beta$-Lactamase genes in extended-spectrum $\beta$-Lactamase (ESBL) and non-ESBL-producing Escherichia coli clinical isolates. Philippine Journal of Science, 146(2): 167-175.

Day, M. J., Hopkins, K. L., Wareham, D. W., Toleman, M. A., Elviss, N., Randall, L., Teale, C., Cleary, P., Wiuff, C., Doumith, M., Ellington, M., Woodford, N. and Livermore, D. M. (2019). Extendedspectrum $\beta$-lactamase-producing Escherichia coli in human-derived and foodchain-derived samples from England, Wales, and Scotland: an epidemiological surveillance and typing study. The Lancet Infectious Diseases, 19(12): 1325-1335.

Ellingson, K., Haas, J. P., Aiello, A. E., Kusek, L., Maragakis, L. L., Olmsted, R. N., Perencevich, E., Polgreen, P. M, Schweizer, M. L, Trexler, P, VanAmringe, M. and Yokoe, D. S. (2014). Strategies to prevent healthcare-associated infections through hand hygiene. Infection Control and HospitalEpidemiology, 35(8): 937-960.

Essack, S. Y., Desta, A. T., Abotsi, R. E. and Agoba, E. E. (2017). Antimicrobial resistance in the WHO African region: current status and roadmap for action. Journal of Public Health (United Kingdom), 39(1): 8-13.

Fair, R. J. and Tor, Y. (2014). Perspectives in medicinal chemistry antibiotics and bacterial resistance in the 21 st Century. Perspectives in Medicinal Chemistry, 2014(6):25-64.

Gashe, F., Mulisa, E., Mekonnen, M. and Zeleke, G. (2018). Antimicrobial resistance profile of different clinical isolates against thirdgeneration cephalosporins. Journal of Pharmaceutics, 2018(1): 5070742

Goldstein, F. W., Gertner, J. and Pe, Y. (1995). Resistance to ceftriaxone and other $\beta$ lactams in bacteria isolated in the community. Antimicrobial Agents and Chemotherapy, 39(11):2516-2519.

Gundran, R. S., Cardenio, P. A., Villanueva, M. A., Sison, F. B., Benigno, C. C., Kreausukon, K., Pichpol, D. and Punyapornwithaya, V. (2019). Prevalence and distribution of bla CTX-M, bla SHV, bla TEM genes in extended- spectrum $\beta$ - Lactamaseproducing $\mathrm{E}$. coli isolates from broiler farms in the Philippines. BMC Veterinary 
Research, 15(1):1-8.

Haller, L., Chen, H., Ng, C., Le, T. H., Koh, T. H., Barkham, T., Sobsey, M. and Gin, K. Y. H. (2018). Occurrence and characteristics of extended-spectrum $\beta$-lactamase- and carbapenemase- producing bacteria from hospital effluents in Singapore. Science of the Total Environment, 615(1): 1119-1125.

Hou, X. H., Song, X. Y., Ma, X. B., Zhang, S. Y. and Zhang, J. Q. (2015). Molecular characterization of multidrug-resistant Klebsiella pneumoniae isolates. Brazilian Journal of Microbiology, 46(3): 759-768.

Huijbers, P. M. C., Graat, E. A. M., Haenen, A. P. J., van Santen, M. G., van EssenZandbergen, A., Mevius, D. J., Duijkeren, E. and van Hoek, A. H. A. M. (2014). Extended-spectrum and AmpC ?lactamase-producing Escherichia coli in broilers and people living and/or working on broiler farms: Prevalence, risk factors and molecular characteristics. Journal of Antimicrobial Chemotherapy, 69(10): 26692675.

Jemima, S. A. and Verghese, S. (2008). Multiplex PCR for bla CTX-M and bla SHV in the extended spectrum beta lactamase (ESBL) producing Gram-negative isolates. Indian Journal of Medical Research, 128(3): 313-317.

Jewoola, O. O., Bode-sojobi, I. O., Ogunsola, F. T. and Okonji, P. E. (2020). High carriage rates of extended-spectrum betalactamase-producing Enterobacteriaceae in children at admission into paediatric wards of a university teaching hospital in Lagos, Nigeria. Nigerian Postgraduate Medical Journal, 27(2): 136-142.

Lewis, C. and Allen, D. (2001). General prescribing principles. Improving practice. Nursing Standard (Royal College of Nursing (Great Britain): 1987), 17(38): 2

Li, B. and Webster, T. J. (2018). Bacteria antibiotic resistance: new challenges and opportunities for implant-associated orthopedic infections. Journal of Orthopaedic Research, 36(1): 22-32.

Obasi, A., Nwachukwu, S. C. and Ugoji, E. (2018). First detection of augmentin and colistin resistant Cronobacter sakazakii from a pharmaceutical wastewater in south- western Nigeria. Environmental DNA, 1(3): 268-280.

Olalekan, A., Onwugamba, F., Iwalokun, B., Mellmann, A., Becker, K. and Schaumburg, F. (2020). High proportion of carbapenemase-producing Escherichia coli and Klebsiella pneumoniae among extended-spectrum $\beta$-lactamaseproducers in Nigerian hospitals. Journal of Global Antimicrobial Resistance, 21: 8-12.

Oli, A. N., Itumo, C. J., Okam, P. C., Ezebialu, I. U., Okeke, K. N., Ifezulike, C. C., Ezeobi, I., Emechebe, G. O, Okezie, U. M, Adejumo, S. A. and Okoyeh, J. N. (2019). Carbapenem-resistant enterobacteriaceae posing a dilemma in effective healthcare delivery. Antibiotics, 8(4): 1-11.

Oteo, J., Navarro, C., Cercenado, E., DelgadoIribarren, A., Wilhelmi, I., Orden, B., Garcia, C., Miguelanez, S., Perez-Vazquez, M., Garcia, C., Aracil, B., Bautista, V. and Campos, J. (2006). Spread of Escherichia coli strains with high-level cefotaxime and ceftazidime resistance between the community, long-term care facilities, and hospital institutions. Journal of Clinical Microbiology, 44(7): 2359-2366.

Otokunefor, K., Tamunokuro, E. and Amadi, A. (2019). Molecular detection of mobilized colistin resistance (mcr-1) gene in Escherichia coli isolates from Port Harcourt, Nigeria. Journal of Applied Sciences and Environmental Management, 23(3): 401.

Paterson, D. L., Hujer, K. M., Hujer, A. M., Yeiser, B., Bonomo, M. D., Rice, L. B., Bonomo, R. A; International Klebsiella Study Group. (2003). Extended-spectrum betalactamases in Klebsiella pneumoniae bloodstream isolates from seven countries: dominance and widespread prevalence of SHV- and CTX-M-type $\beta$ lactamases. Antimicrobial Agents and Chemotherapy, 47(11):3554-3560.

Pitout, J. D. D., Church, D. L., Gregson, D. B., Chow, B. L., McCracken, M., Mulvey, M. R. and Laupland, K. B. (2007). Molecular epidemiology of CTX-M-producing Escherichia coli in the calgary health region: Emergence of CTX-M-15producing isolates. Antimicrobial Agents and 
Chemotherapy, 51(4): 1281-1286.

Ramesh, N. and Sumathi, C. S. (2008). Urinary tract infection and antimicrobial susceptibility pattern of extended spectrum of beta lactamase producing clinical isolates. Biological Research, 2(5): 7882.

Rawat, D. and Nair, D. (2010). Extendedspectrum $\beta$-lactamases in Gram negative bacteria. Journal of Global Infectious Diseases, 2(3): 263-274.

Antibiotics in the 21st century: are we really safe? (2018). EBioMedicine, 38: 1-2.

Rodriguez-Baño, J., Gutiérrez-Gutiérrez, B., Machuca, I. and Pascual, A. (2018). Treatment of infections caused by extended-spectrum-beta-lactamases. Clinical Microbiology Reviews, 31(2): 1-42.

Rossolini, G. M., D'Andrea, M. M. and Mugnaioli, C. (2008). The spread of CTX-M-type extended-spectrum $\beta$-lactamases. Clinical Microbiology and Infection, 14(SUPPL. 1), 3341.
Schechner, V., Temkin, E., Harbarth, S., Carmeli, Y. and Schwaber, M. J. (2013). Epidemiological interpretation of studies examining the effect of antibiotic usage on resistance. Clinical Microbiology Reviews, 26(2):289-307.

Sendall, M. C., McCosker, L. K. and Halton, K. (2019). Cleaning staff's attitudes about hand hygiene in a metropolitan hospital in Australia: a qualitative study. International Journal of Environmental Research and Public Health, 16(6): 1067.

Shaikh, S., Fatima, J. and Shakil, S. (2015). Antibiotic resistance and extended spectrum beta-lactamases?: types, epidemiology and treatment. Saudi Journal of Biological Sciences, 22(1): 90-101.

Podschun, R. and Ullmann, U. (1998). Klebsiella spp. as nosocomial pathogens: epidemiology, taxonomy, typing methods, and pathogenicity factors. Clinical Microbiology Reviews, 11(4): 589-603. 